\title{
Perception towards Nursing Profession among Nurses Working in Public Hospitals in Central Ethiopia: A Mixed-Method Study
}

Meseret Tura ( $\sim$ maseekoo04@gmail.com )

Ambo University

Sagni Fage

Haramaya University

Adamu Birhanu

Ambo University

Tufa Kolola

Ambo University

Ebisa Zerihun

Ambo University

Lemma Mideksa

Ambo University

\section{Research Article}

Keywords: Perception, nurse, nursing profession, Ambo, Ethiopia

Posted Date: January 21st, 2021

DOl: https://doi.org/10.21203/rs.3.rs-149761/v1

License: (9) (i) This work is licensed under a Creative Commons Attribution 4.0 International License. Read Full License 


\section{Abstract}

Background: Nurses' perceptions guide them in maintaining their nursing profession and are dependent on different factors. Although a good perception can help lead a successful profession, many nurses leave the profession in Ethiopia. The aim of this study was to assess the nurses' perception towards their profession and factors associated with it among nurses working in public hospitals in the west Shewa zone, Oromia, Central Ethiopia.

Methods: An institutional based cross-sectional study, a concurrent mixed-methods approach was conducted among randomly selected nurses working in public hospitals in the west Shewa zone from May 25-June 20, 2020. Quantitative and qualitative data were obtained using interview techniques. The quantitative data were analyzed using SPSS version 25 and the qualitative was analyzed through thematic analysis. The strength and direction of the statistical association were measured according to the odds ratio and the $95 \%$ confidence interval. The statistically significant level was reported at $p<0.05$.

Results: In this study, $54.6 \%$ [95\% $\mathrm{Cl}(48.0 \%, 61.0 \%)]$ had a good perception towards nursing profession. Nurses who had Bachelor degree (BSc) [AOR: 3.00 (95\% Cl: (1.55-5.80)], those who earn a monthly salary of $\geq 6194$ ETB [AOR: 2.28 (95\% Cl: 1.01-5.16)], those working in primary hospitals [(AOR: 4.39 (95\%Cl: (1.39-9.95)] and general hospitals [(AOR:6.09(2.84,13.01) were more likely to have good perception towards nursing profession than their counter parts.

Conclusions: Nearly six in ten nurses in the study area had a good perception towards nursing profession. Nurses' level of education, monthly salary scale and type of hospital the nurses were working in should be considered for improving nurses' perception towards their profession and thereby to keep the experienced nurses in their profession.

\section{Background}

Nurses are the largest professional group in healthcare systems [1]. According to Florence Nightingale's theory, nursing has gone from an underpaid and undesirable career to a highly acclaimed and respected profession [2]. Perception is defined as the ability to perceive and take awareness of something through the senses. It can also be defined as an idea, creed or image that you have as a result of the way you see or understand something. Nurses' perceptions of the nursing profession may vary according to their age, education, social and work experience, among other reasons [3].

The impact on the nurses' poor perception of nursing profession results in low job satisfaction and it also leads to an intention to leave their profession thus increasing nurses' shortage and creating a crisis in the nation's health care system which results in poor quality of health care delivery. Nurses' satisfaction with the appreciation of their employer contributes to the nurses' perception of their nursing profession [4]. Many factors might affect the nurses' perceptions towards nursing profession among which individual or personal, social, economic, cultural, spiritual, organizational, and other external professional factors [5]. There have been different perceptions of what it means to be a nurse. Poor perceptions were related to 
gender stereotyping, poor pay, and poor working conditions [6]. On the contrary, nursing has also been perceived as a caring and nurturing profession which demands a higher physical and emotional strength, patience, and knowledge [7].

Although Nurses constitute a majority of health care professionals; they are largely invisible and have been overlooked about what they do and how they do it. The profession is considered to have limited role in decision making, lack of professional confidence, fear, insecurity, and sense of inferiority. Many experienced nurses are leaving this profession or field and young people are not selecting nursing as a potential career. In the United Kingdom (UK) $25 \%$ of nursing students were estimated to leave the profession, and in Canada, $40 \%$ of the nursing students quit their studies. Africa as a whole falls below the minimum standard, with 185 health workers for every 100,000 people. Nursing profession is predominantly recognized as the females' profession and is limited to bedside care and drug administration instead of being considered as skilled and well-educated nursing professionals who could play important roles in health care [9-12].

There is a shortage of nursing professionals in the world. American Association of Colleges Nursing study showed that there will be a shortage of 9 million nurses by the year 2030, which poses a serious threat to patient safety. How individuals perceive themselves and how they are perceived by others are an important part of the relationships between nurses, other health-care providers, and the families they serve [12-16]. There is a scarcity of data on the nurses' perception of the nursing profession and the factors associated with it among nurses working in public hospitals in developing countries, including Ethiopia. Thus, this study aimed to assess nurses' perception towards the nursing profession and associated factors among Nurses working in public hospitals found in the west Shewa zone, Oromia region, Central Ethiopia.

\section{Methods And Materials}

\section{Study Settings}

The study was conducted from May 25 - June 20, 2020, in west Shewa zone, central part of Ethiopia. West Shewa zone is bordered on the south by the southwest Shewa zone and the Southern Nations, Nationalities and Peoples Regional State, on the southwest by Jimma zone, on the West by East Wollega zone, on the northwest by Horo Gudru Wollega zone, on the north by the Amhara Regional State, on the northeast by North Shewa, and on the East by Oromia Special Zone surrounding Finfinne. Its capital Ambo town is located $114 \mathrm{~km}$ to the west from Addis Ababa-the national capital city. According to the report from west Shewa zonal health department, west Shewa had 22 districts with a total population of $26,52,781$ during the study period. The zone had 8 public hospitals, 91 health centers, 482 health posts and a total of 522 Nurses working in those public hospitals.

\section{Study design and Population}


This cross sectional study design used a concurrent mixed-methods approach. All nurses working in public hospitals found in the west Shewa zone during the study period were a source population, while all randomly selected nurses working in public hospitals found in the west Shewa zone were study population.

\section{Sample Size and Sampling Technique}

The sample size was calculated using single population proportion formula with the following assumptions: $95 \%$ confidence interval (Cl), $5 \%$ margin of error, and the prevalence of Nurses perception toward nursing profession ( $p=52.4 \%$ ) from a study done in Debre Birhan town, Ethiopia, 2015 [19]. Thus, the calculated sample size was 384 . Since the source population is $<10,000$, the finite population correction formula was employed and by adding $10 \%$ for non-response rate, the final sample size was found to be 243 . The calculated sample size was proportionally allocated to each public hospital for quantitative part, while the sample size for qualitative part was decided based on data saturation. The study participants were selected though simple random sampling technique by lottery method using their list from each hospital's human resource department as a sampling frame. Accordingly we selected 44 nurses from Ambo General Hospital, 66 nurses from Ambo University Referral Hospital, 19 nurses from Jeldu primary Hospital, 23 nurses from Guder General Hospital, 12 nurses from Bako primary Hospital, 23 nurses from Gindeberet General Hospital, 27 nurses from Incini Primary Hospital, and 24 nurses from Gedo General Hospital. Among the 238 study participants, 15 nurses further consented to take part in the in-depth interview (9 nurses from Ambo University Referral Hospital and 6 nurses from Ambo General Hospital).

\section{Data Collection and Quality Control}

Data were collected using 35 Nursing Dimension Inventory Stem questions which were adopted from the study conducted in UK and Spain [6] was used for quantitative part of this study. The questionnaire was translated from English language to the local language (Afaan Oromoo) translated back to English by two different language experts. The quantitative data collection tool consists of socio-demographic variables, occupational factor, 35 Nursing dimension inventory stem questions, and two questions related to nurses future perceptions towards nursing profession. For the qualitative study, semi-structured interview guide was developed by reviewing literatures and used for an in-depth interview. The questions were used to collect how nurses perceive about nursing profession, what influences the nurses' perception towards nursing profession, and what makes them to quit their job.

For quantitative part, five BSc Nurses collected the data through a face to face interview technique and supervised by two MSc Nurses. For qualitative part, one BSc Nurse collected the data through an in-depth interview conducted in a local language (Afaan Oromoo). The data were recorded by audio recorders supported by note-taking. 
To assure the data quality, the questionnaires were translated in to local languages. The data collectors and supervisors were given one day's orientation on the study tool and the data collection approach. The first author (MRT) provided one day orientation for data collectors and supervisors about the purpose of the study, the tools, ethical issues and the interview approaches. Before the actual data collection, the data collection tools were pre-tested among $5 \%$ of the sample size (12 nurses) in Tullu Bollo hospital which is found in southwest Shewa zone-a nearby zone to the study setting. The reliability and validity of the study tool were estimated. The result of reliability tests showed that Cronbach's alpha for 35 Nurses Dimension Inventory Stem question was 0.83 on pre-test. After pre-test and revision from experts some modifications were incorporated for its validity. Then necessary comments and feedbacks were incorporated in the final instrument.

Qualitative data quality was ensured by enhancing the trustworthiness and rigor of the study findings. The in depth interview records and the note taking were transcribed immediately after the interview was conducted.

\section{Data Processing and Analysis}

The quantitative data collected was verified, entered in EpiData version 3.1 and exported into SPSS version 25 for analysis. The data were cleared by analyzing the frequency and cross-referencing any missing variables in the hard copy. Descriptive statistics were calculated to describe the sociodemographic characteristics of the participants by means of texts, tables and graphs. Binary logistical regression was used to check the association between the result variable and each independent variable. Variables with a p-value lower than 0.25 in the bivariate analysis were considered candidates for multivariate logistic regression analysis. To measure the strength of the association of the result with the independent variables, adjusted odds ratios and a 95\% confidence interval $(\mathrm{Cl})$ were calculated. The suitability of the model was tested by the Hosmer Lemeshow suitability test and therefore the model was deemed fit because it was insignificant (yield $p>0.05$ ). Finally, statistical significance was declared at $p$ value $<0.05$.

The qualitative data were the subject of a thematic analysis. Firstly, all interviews were recorded and the data collector made additional notes. The tape was listened to and the transcripts were read and proofread several times carefully. From the potentially important and tentative scores, the researcher noted the interrelationships, connections and patterns that emerged in the data. The audio recordings were transcribed verbatim, leaving aside the sound of "aahs" and "oohs" to create verbatim written accounts. Thematic analysis was undertaken to identify themes and sub-topics. According to Braun and Clarke, thematic analysis is a method of identifying, analysing and pointing out trends (themes) in the data [26]. It goes through 6 stages of analysis. The analysis process for this study began first, to familiarize the data, note them, and look for patterns of meaning and questions of potential interest in the data. This is followed by initial code generation and theme research, theme review and theme definition 
and naming. Second, coded transcripts were made separately to create a list of topics. In the end, the results were written.

\section{Results}

\section{Socio-demographic characteristics of study participants}

Two hundred thirty eight, (97.9\%) of the participants fully responded to the questionnaires but five (2.1\%) questionnaires were incomplete and rejected from analysis. One hundred thirty (54.6\%) were females. The respondents' age ranges from 22 to 48 years with the mean age of 30.05 (SD \pm 5.190 ) and the majority of the respondents $138(58 \%)$ were in the $20-29$ years age group. About half of the study participants, 124 (52.1\%) were married and 146(61.3\%) were BSc holders. Regarding to work experiences, $128(53.8 \%)$ of respondents had less than five years work experience with the mean year of work $5.81( \pm$ 4.893 SD) (Table 1). 
Table 1

Socio-demographic characteristics of Nurses working in public hospitals of West Shewa zone, Oromia region, Central Ethiopia, $2020(n=238)$.

\begin{tabular}{|c|c|c|}
\hline Variables & Frequency & Percent (\%) \\
\hline \multicolumn{3}{|l|}{ Sex } \\
\hline Female & 130 & 54.6 \\
\hline Male & 108 & 45.4 \\
\hline \multicolumn{3}{|l|}{ Age group (years) } \\
\hline $20-29$ & 122 & 51.3 \\
\hline $30-39$ & 103 & 43.3 \\
\hline $40-49$ & 13 & 5.4 \\
\hline Mean \pm SD & \multicolumn{2}{|c|}{$30.05(S D \pm 5.190)$} \\
\hline \multicolumn{3}{|l|}{ Marital Status } \\
\hline Married & 124 & 52.1 \\
\hline Unmarried & 104 & 43.7 \\
\hline Others ${ }^{a}$ & 10 & 4.2 \\
\hline \multicolumn{3}{|l|}{ Education level } \\
\hline BSc degree & 146 & 61.3 \\
\hline Diploma & 92 & 38.7 \\
\hline \multicolumn{3}{|c|}{ Work experience in years } \\
\hline$\leq 4$ & 128 & 53.8 \\
\hline $5-8$ & 57 & 23.9 \\
\hline$\geq 9$ & 53 & 22.3 \\
\hline Mean \pm SD & \multicolumn{2}{|c|}{$5.81( \pm 4.893)$} \\
\hline \multicolumn{3}{|c|}{ Monthly income in birr } \\
\hline$<3934$ & 38 & 16.0 \\
\hline $3935-6193$ & 75 & 31.5 \\
\hline 6194 and above & 125 & 52.5 \\
\hline Mean \pm SD & \multicolumn{2}{|c|}{$5962.68( \pm 1796.052)$} \\
\hline
\end{tabular}




\begin{tabular}{|llc|}
\hline Variables & Frequency & Percent (\%) \\
\hline Primary Hospital & 116 & 48.7 \\
\hline General Hospital & 65 & 27.3 \\
\hline Referral Hospital & 57 & 23.9 \\
\hline Note: ${ }^{\text {a }}$ separated \& divorced & & \\
\hline
\end{tabular}

\section{Nurses perception towards nursing profession}

The mean perception score of study participants was $119.65(S D=26.844)$. More than half of nurses, $130(54.6 \%)$ [95\% $\mathrm{Cl}(48.0 \%-61.0 \%)]$ had good perception towards nursing profession and the remaining $45.4 \%(n=108)$ had poor perception (Fig. 1).

\section{Why nurses want to leave their profession}

Among the study participants of this study, 117 (49.2\%) reported they have an intention to leave the nursing profession. The main reason that caused an intention to leave nursing profession was work burden, $52.14 \%$ (88), followed by low salary which was $35.04 \%$ (Fig. 2).

Figure 2: The reasons to leave the nursing profession among nurses working in public hospitals in the west Shewa zone, Oromia region, Central Ethiopia, $2020(n=117)$.

\section{Factors Associated with Nurses' Perception}

In a bivariate logistic regression analysis; sex, educational status, year of work experience, monthly income, and the types of hospital Nurses working in were significantly associated with nurse's perception towards their profession.

In multivariable logistic regression analysis, only educational status, monthly income and the types of hospital nurses were working in sustained their association with nurse's perception towards their profession. Those nurses who had a Bachelor degree (BSc) were 3 times more likely to have good perception than those nurses who had diploma [AOR: 3.00 (95\% Cl: (1.55-5.80)] and those who earn a monthly salary of 6194 ETB and above were 2.28 times more likely to have good perception than those who get less than 3934ETB [AOR: 2.28 (95\% Cl: 1.01-5.16)]. The likelihood of having a good perception was 4.39 times more likely among Nurses who were working in primary hospitals compared to those who work in Referral Hospital [(AOR: 4.39 (95\% Cl: (1.39-9.95)]. Those nurses working in general hospitals were 6.09 times more likely to have good perception than those who were working in Referral Hospital [(AOR: 6.09 (95\%Cl: (2.84-13.01)] (Table 2). 
Table 2

Factors associated with nurses perception among Nurses working in public hospitals in the west Shewa zone, Oromia region, Central Ethiopia, $2020(\mathrm{n}=238)$.

\begin{tabular}{|c|c|c|c|c|c|}
\hline \multirow[t]{3}{*}{ Variables } & \multirow[t]{3}{*}{ Category } & \multicolumn{2}{|c|}{ Perception } & \multirow[t]{3}{*}{$\operatorname{COR}(95 \% \mathrm{Cl})$} & \multirow[t]{3}{*}{$\mathrm{AOR}(95 \% \mathrm{Cl})$} \\
\hline & & Good & Poor & & \\
\hline & & $\mathrm{N}(\%)$ & $N(\%)$ & & \\
\hline \multirow[t]{2}{*}{ Sex } & Male & $54(50.0)$ & $54(50.0)$ & $\begin{array}{l}0.71(0.43 \\
1.19)^{\star}\end{array}$ & $0.67(0.38,1.18)$ \\
\hline & Female & $76(58.5)$ & $54(41.5)$ & 1 & 1 \\
\hline \multirow[t]{2}{*}{ Educational status } & Diploma & $57(62.0)$ & $35(38.0)$ & 1 & 1 \\
\hline & BSc degree & $73(50.0)$ & $73(50.0)$ & $\begin{array}{l}\text { 1.63(0.96, } \\
2.77)^{\star}\end{array}$ & $3.00(1.55,5.80)^{\star \star}$ \\
\hline \multirow[t]{3}{*}{ Work experience } & $\leq 4$ years & $65(50.8)$ & $63(49.2)$ & 1 & 1 \\
\hline & $5-8$ years & $35(61.4)$ & $22(38.6)$ & $\begin{array}{l}\text { 1.54(0.82, } \\
2.91)^{\star}\end{array}$ & $0.57(0.23,1.41)$ \\
\hline & $\geq 9$ years & $30(56.6)$ & $23(43.4)$ & $\begin{array}{l}1.26(0.66 \\
2.41)\end{array}$ & $1.267(0.55,2.93)$ \\
\hline \multirow[t]{3}{*}{ Monthly income in Birr } & $<3934$ & $16(42.1)$ & $22(57.9)$ & $\begin{array}{l}0.67(0.31 \\
1.47)\end{array}$ & $0.61(0.20,1.89)$ \\
\hline & $3935-6193$ & $73(60.3)$ & 48(39.7) & $\begin{array}{l}1.41(0.80 \\
2.50)^{\star}\end{array}$ & $2.28(1.01,5.16)$ ** \\
\hline & $\geq 6194$ & $41(51.9)$ & $38(48.1)$ & 1 & 1 \\
\hline \multirow[t]{3}{*}{$\begin{array}{l}\text { Types of hospital } \\
\text { Nurses work in }\end{array}$} & $\begin{array}{l}\text { Primary } \\
\text { Hospital }\end{array}$ & 18(31.6) & $39(68.4)$ & $\begin{array}{l}0.33(0.16 \\
0.69)^{\star}\end{array}$ & $4.39(1.93,9.95)^{\star \star}$ \\
\hline & $\begin{array}{l}\text { General } \\
\text { Hospital }\end{array}$ & $74(63.8)$ & $42(36.2)$ & $\begin{array}{l}1.25(0.67 \\
2.33)\end{array}$ & $6.09(2.84,13.01)^{\star \star}$ \\
\hline & $\begin{array}{l}\text { Referral } \\
\text { Hospital }\end{array}$ & $38(58.5)$ & $27(41.5)$ & 1 & 1 \\
\hline
\end{tabular}

\section{Themes}

Fifteen in-depth interviews were conducted. Three main themes emerged from the data, and these were 1. Nurses' characteristics and content of nursing work 2. What influences the nurses' perception about the nursing profession, and 3 . What makes nurses to quit their jobs or leave their nursing profession? These are supported by quotes in nurses' own words. 


\section{Theme 1:}

\section{Nurses characteristics}

This theme emerged from five in-depth interviews during which nurses described their perceptions towards nursing profession. Nurses highlighted a Nurse's characteristics when Nurses were well in physical conditions. They described a suitable character for nurse as brave, social, and which requires the ability to cope with stress and good physical condition. "As a Nurse you have to lift people frequently and thus must be in a good physical condition so that you are able to do that. Nurses have to lift patients and move them from one place or position to another, feed patients, take them to the toilet and help them to the shower." (A 33 years male nurse from Ambo General Hospital)

\section{Content of nursing work}

This theme emerges from seven interview participants. Theoretical competence was described as a legal competence related to nursing work. Understanding the rights, responsibilities and competences related to the laws that guide the work and knowledge in anatomy, physiology, hygiene, equipment needed and medications related to nursing work. Working skills such as professional nursing skills, communication skills and management skills are needed in the nursing profession. Nurses recognized nursing tasks such as helping and caring for patients, being beside the patients and making independent decisions in the nursing profession. "In my experiences, nurses were seen as assistants to doctors who have an assistance role in patient care. For instance, nurses were said to support and assist doctors and should perform all the tasks left over by doctors. I think if Nurses have to take every order from physicians/doctors and must apply it; there is no need to waste four years in university/colleges/nursing schools to graduate in BSc Nursing." (A 36 years male nurse from Ambo University Referral hospital) Said," Nurses have no power to decide on anything rather than doing what they are ordered by doctor." Nurses are making no decisions; physicians are in position to make overall decisions in patient cares. Almost all the decisions come from doctors even to give pain killers such as paracetamol."

\section{Career development in nursing profession}

A career in nursing was discussed among nurses through education opportunities, nurses' employment conditions and future career options in 'nursing. One Nurse gave the following explanation: "I know many Nurses who worked for more than ten years in public hospitals without getting any opportunity for further education. Getting the opportunity for further education remained very rare in this hospital." (A 29 years female nurse from Ambo University Referral hospital)

\section{Theme 2:}




\section{Personal factors}

Personal factors include skills acquired and knowledge of the nurse which determine how she/he responds to the physical, cognitive and psycho-social demands of the work. Included among these factors are committed to patient care, personal values, and self-confidence. Provided the following explanation: "I believe that Nurses must be strong enough physically, knowledgeable and cooperative. But, what I have seen in this hospital was different. Some of the nurses act carelessly in their daily activities." (A 29 years female nurse from Ambo University Referral hospital)

\section{Family members related factors}

Family members influence nurse's perceptions. Especially husband's influence was seriously mentioned during the interviews. One female Nurse reported that her husband is against her activities in nursing, hoping for something better. Another Nurse said "My husband frequently asked me to resign my job as a nurse. He always told me not to continue with nursing because he doesn't want me to be wound care provider or dressing changer." (A 35 years male nurse from Ambo University Referral hospital)

\section{Media related factors}

The nurses described using media such as the internet, radio and television to get information about the nursing profession. However, the media's view about nursing was reported as being negative. The real image of nursing should be promoted and Nurse Academicians need to be more active in public discussions or on media and raise the visibility of nursing science/profession to support and promote professionalism. "Nurses work in the hospital and the views of the general public for nurses are very far away from the reality. So, I think that media must be able to work on these gaps and nurse educators must influence the stakeholders to expose really who the nurses are." (A 27 years female nurse from Ambo General Hospital)

\section{External professionals' factors}

A close teamwork is an essential element in healthcare. Nurses were seen to work in collegial teams and also with other healthcare professionals, such as doctors, midwifes, and laboratory personnel's. "Many health care professional take care of a single patient. So, as a nurse you have to be able to work and communicate with them. But nurses were meant to report the patients' information to the doctors and consult them when needed. However, in reality most of the time the relationship is described with nurses being inferior to doctors and nurses are considered as doctors' helpers." (A 28 years male nurse from Ambo University Referral hospital) "I think that my colleagues are helpful and supportive. There is a good cooperation between nurses in surgical ward." (37 years male nurse from hospital) 


\section{Occupational factors}

Occupational factors are characteristics of the scope of practice, interdisciplinary relationships, nature and role of the profession. These factors are the scope of practice, level of autonomy and interdisciplinary relationships. One Nurse said: "I have seen many nurses in this hospital; they did not know the scope of their nursing practice and some of them were practicing out of their job descriptions. Nursing is working to get many other positive aspects than salary. Pleasure of helping others was mentioned as a positive side of nursing work." (A 39 years male nurse from Ambo General Hospital)

\section{Theme 3}

\section{Work habit}

Four participants felt that the heavy workload was difficult to manage effectively within the working hours in a day. One nurse said that: "I will change my job within the coming one year because of the heavy work burden, low salary, bad attitude of the physicians for nurses, how the chronic nurses'(nurses who worked longer years) especially female nurses perceive their profession and the image the general public have for the nursing profession." (A 27 years male nurse from Ambo University Referral hospital)

\section{Educational career}

Nursing education was described as an opportunity for further education as good for a nurse. "As to me, there is a limited chance for professional development. I have been working for six years in this hospital, but till now I did not get chance for further education. Not only me, but also I have one friend who have worked for several years and changed his profession because of lack of opportunity for education. So, within short period of time I will be changing my profession." (A 41 years female nurse from Ambo University Referral hospital)

\section{Administration issues}

One nurse said that: "I do not allow anyone to give me unfair decision from the administrative bodies. Last time I saw a nurse who breaks a rule in this hospital and got written warning letter, but similarly I saw a physician with similar mistake but did not get even an oral warning. Upon seeing such a very biased treatment, I decided to leave the profession." (A 28 years male nurse from Ambo General Hospital)

\section{Discussion}

This study was conducted to assess the perception of nurses towards nursing profession and factors associated with it among nurses working in public hospitals of west Shewa zone, central Ethiopia. We 
found that more than half, $54.6 \%$ [95\% $\mathrm{Cl}(48.0,61.0)]$ of study participants had good perception towards nursing profession. Educational status, monthly income and types of hospital nurses were working in were factors associated with their perception towards nursing profession.

The prevalence of good perception in this study is consistent with similar previous studies from Debre Berhan, Ethiopia (52.4\%) [19] and Addis Ababa, Ethiopia (56\%) [22].However, it is lower than the study done at Mekelle Town in Tigray, where $124(91.8 \%)$ of nurses had a favorable attitude for nursing profession [20]. This difference might be attributed to differences in the study settings, variations in the sample size, and differences in sampling techniques.

We found that nurses who had Bachelor degree (BSc) were more likely to have good perception towards nursing profession than those nurses who had diploma. Similar findings were obtained from Addis Ababa, Ethiopia [22]. This might be because as the educational level advances, the awareness about the role of a nurses and job description could increase resulting in a better perception.

Furthermore, nurses who earn monthly salary of $\geq 6194$ Ethiopian Birr (ETB) were more likely to have good perception than those who earn $<3934$ ETB. Similar findings were previously reported from Debre Berhan, Ethiopia [19] and Malaysia where good salary; stability and low stress were the primary factors that influence joining nursing profession [17]. This implies that as the nurses get increase in their monthly salary, their perception towards the nursing profession also gets increased.

Nurses working in Primary and General Hospitals were more likely to have good perception than those who work in a Referral Hospital whereas nurses working in General Hospital. This finding is similar with study reports from Addis Ababa, Ethiopia [22].

In the current study, we found that nearly half, $117(49.2 \%)$ of the nurses who participated in this study had an intention to leave their profession. The main reason to cause an intention to leave their nursing profession was reported as work burden $88(52.14 \%)$ and the second leading cause was low salary ,56(35.04\%).This finding is lower as compared to the previous Ethiopian studies from Debre Birhan (53.4\%) [19], Jimma town (56.4\%) [23] and Addis Ababa (71.5\%) [22] Ethiopia and also American nurses had an intention to leave their profession because of workload; burnout and quality of care at the workplace that has also influenced nurses' intention to leave their job [21,24]. These differences might be due to recent salary increment for nurses in Ethiopia which could have positively influenced their perception and intention. The qualitative study also supported this idea as one of the participant revealed "I will change my job due to work burden, low salary, and pressure from physician, how the chronic nurses' especially female nurses' perceive their profession and the view of the general public have for nursing profession".

This study also revealed that personal factors, family members, media, occupational factors, and other health care providers influence nurses' perception towards nursing profession. This is in line with the previous studies in Addis Ababa, and Debre Berhan, Ethiopia in which occupational (50\%), individual (20\%), salary $(71.8 \%)$, skill and knowledge of nurses $(52.4 \%)$, policies and regulations at the 
provincial/territorial, national and international level (34.0\%) respectively were factors that affect nurses perception towards nursing profession $[19,22]$. The qualitative aspect of this study has supported this finding as one respondent stated." I believe that nurses must be physically strong, knowledgeable and cooperative. But, what I have seen in this hospital was different. Some nurses act carelessly.

Nurses who participated in the present study highlighted that, "Nurse thinks to change the jobs within the coming one year because of work burden, low salary, and bad attitude physicians had for nurses and most of the decisions come from doctors even to give pain killers such as paracetamol". This finding was supported by study from Iran which has revealed that 'one Nurse was happy with her job as a nurse but she is working with few leave or rest and with low salary and 'I do not know who I am. Am I a nurse, auxiliary nurse or secretary? We are responsible for everything because there is no enough staff. Many times patients may suffer from pain for a couple of hours, and I cannot give him/her even one acetaminophen (pain medication) without doctors' order [24].This clearly indicated that there is an influence from physicians, salary, stressful working environments and others that could result in nurses change their nursing profession.

One of the strengths of this study was that it used a mixed method approach not to miss the qualitative factors that could affect nurses' perception. But, since the in-depth interviews were conducted only in Ambo General and Ambo University Referral Hospitals which might not fully represent the conditions of nurses working in the remaining public hospitals. Cross-sectional nature of the study could not enable it to establish cause effect relationship between the outcome variable and the covariates.

\section{Conclusions}

Nearly six in ten nurses in the study area had a good perception towards nursing profession. Nurses' level of education, monthly salary scale and type of hospital the nurses were working in should be considered for improving nurses' perception towards their profession and thereby to keep the experienced nurses in their profession.

\section{Declarations}

\section{Ethical approval and consent to participate}

An ethical approval to conduct this study was obtained from the ethical clearance committee of Ambo University, College of Medicine and Health Science (Ref. No: PG/40/2020). An official letter was sent to west Shewa zonal health department. Informed consent was obtained from all participants for their participation after the nature of the study is fully explained to them in their local languages. The study participants were informed that data will be kept private and confidential and used only for research purposes. Confidentiality of the responses was maintained by coding. Personal privacy and cultural norms were maintained as promised. All methods were carried out in accordance with relevant guidelines and regulations. 


\section{Consent for Publication}

Not applicable.

\section{Availability of data and materials}

The data and all supporting materials used in preparation of this manuscript are freely available from the corresponding author on reasonable request.

\section{Competing interests}

No conflict of interest has been declared by the authors.

\section{Funding}

The funding for this study was obtained from Ambo University as part of master thesis for the first author (MRT). The funding body has no role in designing the study, collection, analysis, and interpretation of data, in writing the manuscript and whether to publish the paper or not.

\section{Authors' contributions}

Proposal writing: MRT, AB, SGF \&TK. Study design: MRT, AB, \& TK. Data collection: MRT, AB, EZ, LM \& TK. Data analysis: MRT, AB, SGF, \&TK. Manuscript writing: MRT, AB, SGF\& TK. Mentorship \& supervision of the entire work: MRT, AB, SGF \& TK. All the authors contributed adequately to the completion of this study. All authors have read and approved the manuscript.

\section{Acknowledgements}

The authors are thankful to Ambo University for the financial supports to conduct this study. Our thanks also goes to west Shewa zonal health office staffs, the study participants, data collectors and field supervisors for their direct or indirect contributions to this study.

\section{References}

1. Teresa O' Hanlon. Define professionalism in nursing, 2010, accessed on January, 2019.

2. Kozier B, Erb G, Berman A. Fundamentals of Nursing Concepts, Process, and Practice. Person Education. 2008;P: 4 
3. Hornbey A. The Advanced learner's Dictionary of Current English, 6th edition, Oxford University press; 2000, p. 864.

4. Lewis $M$, Urmston J. Flogging the dead horse: the myth of nursing empowerment? Journal of Nursing Management; 2000; 8-13.

5. Registered Nurses Association of Ontario, Healthy Work Environment Best practice Guidelines, Professionalism in Nursing, March 2007. P.16-22.

6. Roger W, lan J, Amandah L, Wytze V, Carmen R, Maribel B, et al. Perceptions of nursing: a study involving nurses, nursing students, patients and non-nursing students. International Journal of Nursing Studies; 2002. Accessed on December 30, 2019.

7. Shafeah M. Nurses' Perceptions of Nursing as a Profession and Its Impact on Their Intention to Leave Their Career. IOSR, Journal of Nursing and Health Science; 2016.p20. DOI: 10.9790/19590602041323

8. Salamonson Y, Everett B, Cooper M, Lombardo L, Weaver R, Davidson PM. Nursing as first choice predicts nursing program completion. Nurse Educ. 2014; 34: 127-31.

9. Brodie D, Andrewa G, Andrews J. Perception of nursing. International Journal of Studies; 2004. Accessed on December 25, 2019.

10. American Association of Colleges of Nursing, (AACN). Fact sheet: Nursing shortage. 2017; http://www.aacn. Accessed December 25, 2019.

11. Safadi RR, Saleh MYM, Nassar OS, Amre HM, Froelicher ES. Nursing Students perceptions of nursing: a descriptive study of four cohorts. International Nursing Review; 2011. p54. Accessed February, 2019.

12. Jamie White. The image of nursing: what it is and how it needs to change, Jones \& Bartlett Learning 86-106.

13. Moore M, Perceptions of Nurses and Mothers in Four Studies of the Peripartum Period, 2004, Accessed on October 18, 2020.

14. Ibrahim A, Tawfiq A. Associate nursing students' perceptions toward nursing profession in Jordan. European Scientific Journal; 2013. ISSN: 1857 - 7881.

15. Donelan K, Desroches C, Dutwin D. Public perception of nursing careers; 2008, accessed on February $11,2020$.

16. Prudence PMN, Samuel A, Gladstone FA, Edward A. Psychosocial Factors Influencing the Perception and Choice of Nursing as a Profession. Psychology and Behavioral Sciences; 2014. p.25-32. Doi: 10.11648/j.pbs.20140301.15

17. Asma K, Muhammad A. Iram M, Ali WB, Syed AG. Assessment of Nursing Student Perception Towards, Nursing Profession in Sir Ganga Ram Hospital and Ittefaq Hospital Trust Lahore, Pakistan. Sci. Int. (Lahore), 2017, 29(4), 783-789.

18. Farida S. Abdelmaksoud, Nadia TM, Eglal AAW. Nursing Staff 'Perception Regarding Factors Affecting their Performance in Selected Governmental Hospitals in Egypt. Med. J. Cairo Univ.; 2017, 
85(2), 795-800.

19. Mikiyas AG, Addis AG, Bogale ES. Assessment of Nurse's Perception towards their Profession and factors affecting it in Debre Berhan Town Governmental Health Institution, Debre Berhan, Ethiopia. American Journal of Nursing Science. Vol. 4, No. 6, 2015, p. 297-304. doi:

10.11648/jajns.20150406.11

20. Zaid TG, Gerezgiher BA. Assessment of Nurses Knowledge and Attitude towards Nursing Profession at Public Hospitals in Mekelle Town, Tigray, Ethiopia. Global Journal of Medical Research; 2017, p.12-13.

21. Hanaa HM, Ahmed KS. Assessment of Nurses' Perception about the Nursing Profession in AlJamhory Teaching Hospital. Monsul Journal of Nursing; 2014, p.65-66.

22. Liya W. Assessment of nurses' perception towards nursing profession in public hospitals under Addis Ababa Health Bureau, Ethiopia, 2011.

23. Gizaw AB, Lema TB, Debacho WW, Geremossa GM. Intention to Stay in Nursing Profession and Its Predictors among Nurses Working in Jimma Zone Public Hospitals, South West Ethiopia. J Nurs Care; 2018, 7: 440. Doi:10.4172/2167-1168.1000440.

24. Atefi N, Abdullah KL, Wong LP, Mazlom R. Factors influencing registered nurses perception of their overall job satisfaction: a qualitative study. International Nursing Review; 2014, (61). p352-360

25. Mohsen AH, Marzieh K, Negin MA. Nurses' perception of occupational stress and its influencing factors: in Kashan University of Medical Sciences, Kashan, Iran, 2012. Accessed date on October 23, 2020.

26. Braun V, Clarke V. Using thematic analysis in psychology. Qualitative Research in Psychology, 2006, 3 (77-101).

\section{Figures}




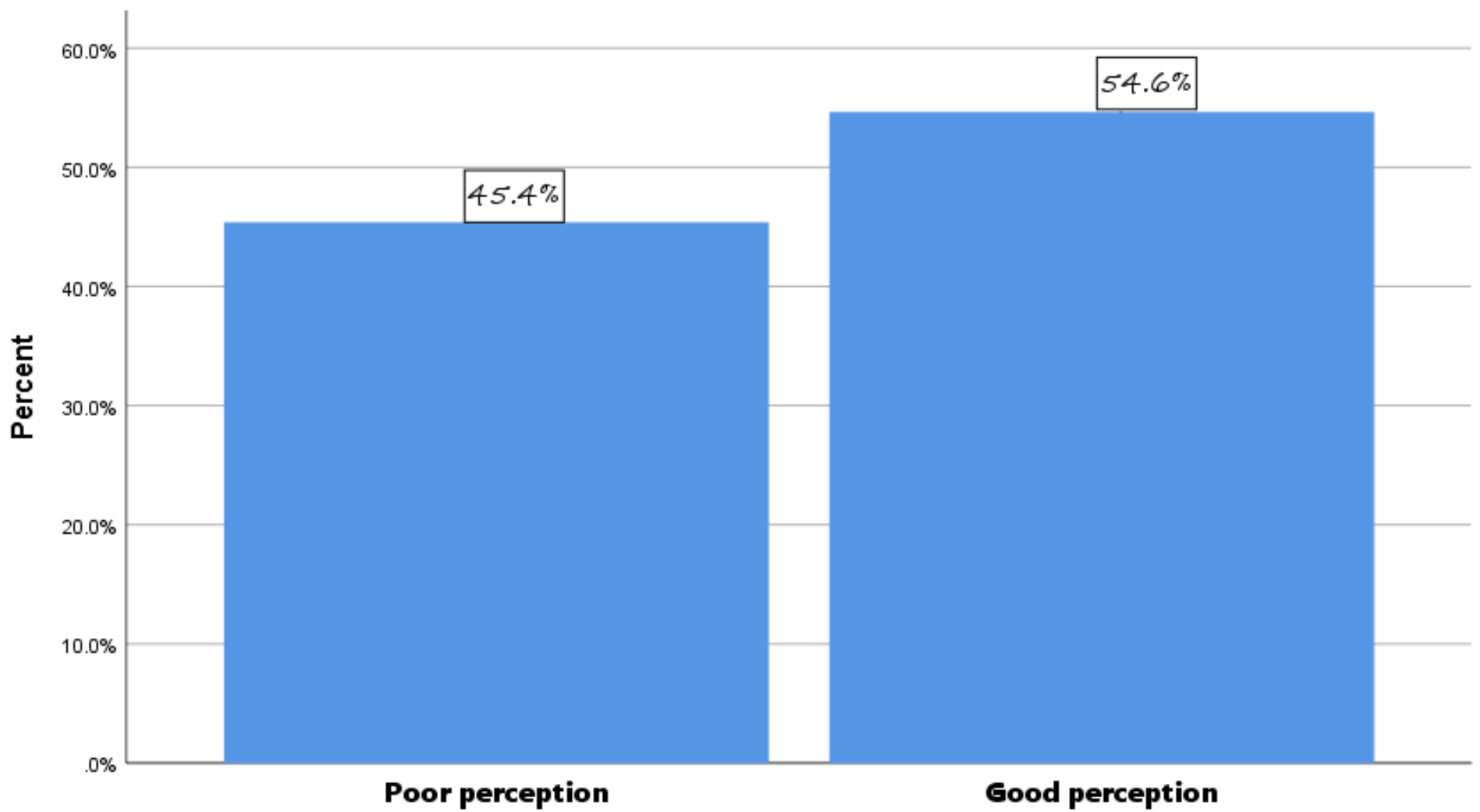

\section{Figure 1}

Nurses perception towards nursing profession among Nurses working in public hospitals in the west Shewa zone, Oromia region, Central Ethiopia, $2020(n=238)$. 

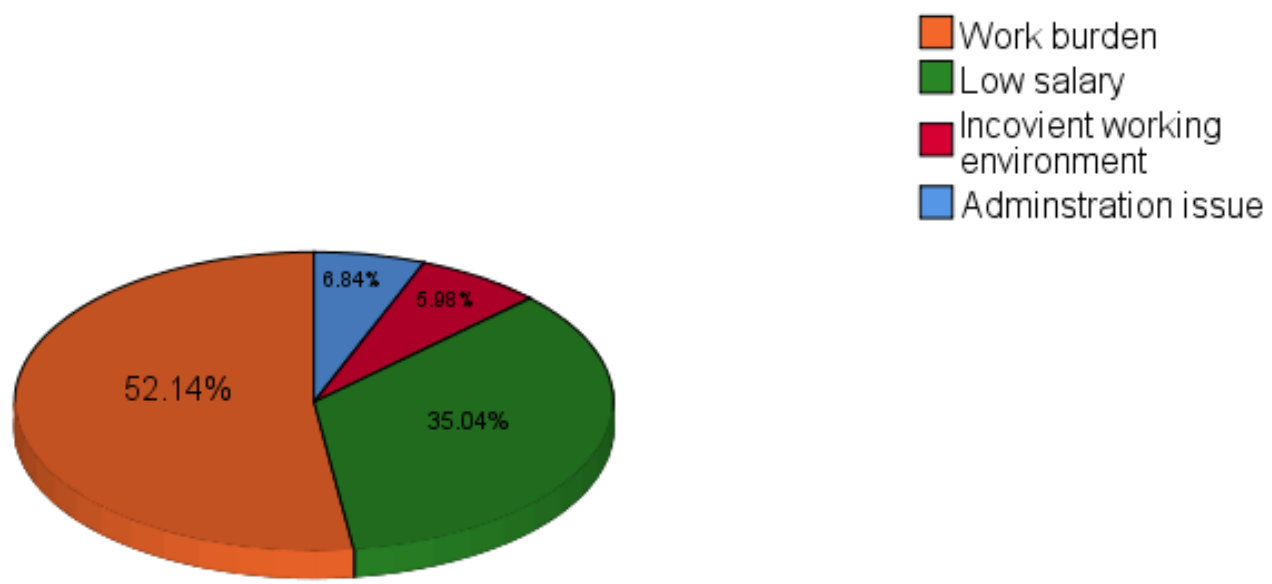

Figure 2

The reasons to leave the nursing profession among nurses working in public hospitals in the west Shewa zone, Oromia region, Central Ethiopia, $2020(n=117)$. 